\title{
Educação e trabalho: a formação de consenso na sociedade sob a influência do capital
}

\section{Education and work: consensus formation in society under the influence of capital}

DOI: 10.46814/lajdv2n6-016

Recebimento dos originais: 01/09/2020

Aceitação para publicação: 30/10/2020

\author{
Adriele A. Inacio \\ Doutoranda em Serviço Social - UFSC \\ Rua Rosalvo Petrechen, 241 - Pitanga Pr. \\ E-mail: adrieleinacio@yahoo.com.br \\ Tatiani Maria Garcia de Almeida \\ Doutora em Educação - UTP \\ Rua Rui Barbosa, 210. Bairro Pitanguinha \\ E-mail: tatianigalmeida@gmail.com \\ Gilson Mezarobba \\ Doutor em Educação - UTP \\ Rua Rui Barbosa, 210. Bairro Pitanguinha \\ E-mail: gilsonmezza@yahoo.com.br
}

\section{RESUMO}

Este artigo tem como objetivo discutir a íntima relação entre educação e trabalho e como ocorreu a sua separação. Isto é, compreender a cisão na unidade educação antes identificada com o processo do trabalho e agora dividida entre a educação propedêutica e a técnica engendrada pelo capital. Para tanto, é necessário compreender que a educação contribui para a conservação da sociedade ao reproduzir seus conteúdos ideológicos. Dessa maneira, o processo de institucionalização da educação acontece correlato ao processo de surgimento da divisão do trabalho. A separação da educação e trabalho teve uma dupla manifestação: a proposta dualista de escolas profissionais para os trabalhadores e escola de ciências e humanidades para os futuros dirigentes; e a proposta de escola única diferenciada, que efetuava internamente a distribuição dos educandos segundo as funções sociais para as quais se os destinavam em consonância com as características que geralmente decorriam de sua origem social, portanto, reforça a sociedade de classes.

Palavras-chaves: Educação, Profissionalização, Ideologia, Hegemonia e Consenso.

\begin{abstract}
This article aims to discuss the intimate relationship between education and work and how it separated. That is, to understand the split in the education unit previously identified with the labor process and now divided between propaedeutic education and the technique engendered by capital. Therefore, it is necessary to understand that education contributes to the conservation of society by reproducing its ideological contents. In this way, the process of institutionalization of education is correlated with the process of emergence of the division of labor. The separation of education and work had a dual manifestation: the dualistic proposal of professional schools for workers and a
\end{abstract}


science and humanities school for future leaders; and the proposal of a unique differentiated school, which internally distributed the students according to the social functions for which they were assigned in line with the characteristics that generally stemmed from their social origin, therefore, reinforces class society.

Keywords: Education, Professionalization, Ideology, Hegemony and Consensus.

\section{INTRODUÇÃO}

Este artigo tem como objetivo discutir a íntima relação entre educação e trabalho e como ocorreu a sua separação. Isto é, compreender a cisão na unidade educação antes identificada com o processo do trabalho e agora dividida entre a educação propedêutica e a técnica engendrada pelo capital. Além disso, é necessário entender que a educação contribui para a conservação da sociedade ao reproduzir seus conteúdos ideológicos. Ao passar às novas gerações esses conteúdos, a educação reproduz as relações sociais que se sustentam, entre outras pela ideologia.

A pesquisa é de cunho bibliográfico que, de acordo com Lakatos e Marconi (1991), tem por finalidade conhecer as diferentes formas de contribuição científica que se realizaram sobre determinado assunto ou fenômeno apresentado.

Segundo Mészáros (2006), uma das funções principais da educação formal nas nossas sociedades é produzir tanta conformidade ou "consenso" quanto for capaz, a partir de dentro e por meio dos seus próprios limites institucionalizados e legalmente sancionados. Para compreender como ocorre essa formação de consenso na sociedade através da educação devemos entender primeiramente a ligação entre trabalho e educação e posteriormente entender como ocorreu a sua separação.

Trabalho e educação sempre estiveram intimamente ligados. Tanto um quanto o outro são atividades essencialmente humanas, ou seja, apenas o ser humano trabalha e educa. Nesse sentido:

Podemos distinguir o homem dos animais pela consciência, pela religião ou por qualquer coisa que se queira. Porém, o homem se diferencia propriamente dos animais a partir do momento em que começa a produzir seus meios de vida, passo este que se encontra condicionado por sua organização corporal. Ao produzir seus meios de vida, o homem produz indiretamente sua própria vida material (MARX \& ENGELS, 1996, p. 27).

Marx em O Capital, Volume I, compara a atividade produtiva do homem e a atividade produtiva dos animais, pois os animais também constroem, no entanto, o animal somente produz sob o imperativo das necessidades físicas imediatas, enquanto que o ser humano produz mesmo quando não possui esse imperativo. Ainda, segundo Marx, uma aranha realiza operações que se 
assemelham às de um tecelão e as abelhas poderiam humilhar alguns arquitetos com as células que faz na cera, mas o que os diferencia é que tanto o tecelão quanto o arquiteto precisam construir mentalmente, para depois realizar. Desse modo, o animal é programado por sua natureza e por isso não modifica as suas condições de vida, apenas responde instintivamente ao meio. Os homens, por sua vez, criam e recriam sua existência pela ação consciente do trabalho (LUKÁCS, 1979).

Dessa forma, o ato de produzir seus meios de vida e de transformar a natureza em função das necessidades humanas é o que denominamos de trabalho. E se a existência humana não é garantida pela natureza, se não é uma dádiva natural, mas tem de ser produzida pelos próprios homens, ela é então um produto do trabalho. Isso significa que o homem não nasce homem, ele forma-se homem, ele não nasce sabendo produzir-se como homem (SAVIANI, 2007). Assim, ele necessita aprender a ser homem, precisa aprender a produzir sua própria existência. A produção do homem é, ao mesmo tempo, a formação do homem, isto é, um processo educativo.

Os homens aprendiam a produzir a sua existência no próprio ato de produzi- la. Aprendiam a trabalhar trabalhando. Transformando a natureza, relacionando-se uns com os outros, os homens educavam-se e educavam as novas gerações. Segundo Saviani (2007), a produção da existência implica o desenvolvimento de formas e conteúdos cuja validade é estabelecida pela experiência, o que configura um verdadeiro processo de aprendizagem. Assim, enquanto os elementos não validados pela experiência são afastados, aqueles cuja eficácia corrobora necessitam ser preservados e transmitidos às novas gerações para a continuidade da espécie.

Ao longo da história podemos notar esta ligação entre trabalho e educação. Nas comunidades primitivas os homens apropriavam-se coletivamente dos meios de produção da existência e nesse processo educavam-se e educavam as novas gerações. Nesse período prevalecia o modo de produção comunal, também denominado de "comunismo primitivo", ou seja, não havia a divisão em classes. Tudo era feito em comum. Na tribo dava-se a apropriação coletiva da terra, constituindo a propriedade tribal na qual os homens produziam sua existência em comum e se educavam neste mesmo processo (SAVIANI, 2007). Nessas condições, a educação identificava-se com a vida.

Entretanto, o desenvolvimento da produção conduziu à divisão do trabalho e, consequentemente, à apropriação privada da terra, provocando uma ruptura na unidade vigente nas comunidades primitivas. A apropriação privada da terra, então o principal meio de produção, gerou a divisão dos homens em classes. Configurando-se, em conseqüência, duas classes sociais fundamentais: a classe dos proprietários e a dos não proprietários. Se a essência humana é definida pelo trabalho, isso significa que ninguém pode viver sem trabalhar, no entanto, com o advento da 
propriedade privada tornou-se possível para a classe dos proprietários viverem do trabalho alheio. E, como afirma Saviani (2007), os nãos proprietários passaram a ter a obrigação de, com o seu trabalho, manterem-se a si mesmos e ao dono da terra.

A divisão dos homens em classe irá provocar uma divisão também na educação. Haverá, assim, uma cisão na unidade da educação, antes identificada com o próprio processo do trabalho.

A partir do escravismo antigo passaremos a ter duas modalidades distintas e separadas de educação: uma para a classe proprietária, identificada com a educação dos homens livres, e outra para a classe não proprietária, identificada como a educação dos escravos e serviçais. A primeira centrada nas atividades intelectuais, na arte da palavra e nos exercícios físicos de caráter lúdico ou militar. E a segunda, assimilada ao próprio processo do trabalho (SAVIANI, 2007, p. 155).

Essa divisão permeará toda a história da educação até os nossos dias. Uma educação para as classes dirigentes, para os proprietários, uma educação humanística, propedêutica e elitizada, enquanto que a classe despossuída de propriedade terá uma educação diferenciada, técnica, limitada apenas ao mundo do trabalho.

\section{A INSTITUCIONALIZAÇÃO DA EDUCAÇÃO E A DIVISÃO DO TRABALHO}

A primeira modalidade de educação deu origem à escola. A própria palavra escola deriva do grego e significa tempo livre, local do ócio. Desenvolve-se uma forma específica de educação, em contraposição àquela inerente ao processo produtivo.

Dessa maneira, o processo de institucionalização da educação acontece correlato ao processo de surgimento da divisão do trabalho. Nas sociedades primitivas, caracterizadas pelo modo coletivo de produção da existência humana, a educação consistia em uma ação espontânea, não diferenciada das outras formas de ações desenvolvidas pelo homem, coincidindo inteiramente com o processo do trabalho que era comum a todos os membros da comunidade, com a divisão dos homens em classes a educação também resulta dividida. Diferencia-se a educação destinada à classe dominante daquela a que tem acesso à classe dominada.

De acordo com Saviani (2007), é aí que se localiza a origem da escola. A educação dos membros da classe que dispõe de ócio, de tempo livre para organizar-se na forma escolar, contrapondo-se à educação da maioria, que continua a coincidir com o processo de trabalho. No Egito, desde as primeiras dinastias até o surgimento do escriba, assim como na Grécia, em Roma e na Idade Média, cujas escolas, restritas, cumpriam a função de preparar os também restritos quadros dirigentes (intelectuais) então requeridos. 
Nesses contextos, as funções manuais não exigiam preparo escolar. A formação dos trabalhadores dava-se com o concomitante exercício das respectivas funções. Mesmo no caso das corporações de ofício, que atingiram alto grau de especialização do artesanato na Idade Média, o sistema de aprendizado ficava a cargo das próprias corporações de ofício, cujo aprendiz adquiria o domínio do ofício exercendo-o juntamente com os oficiais, com a orientação do "mestre de ofício". Dessa forma, o desenvolvimento da sociedade de classes, especificamente nas suas formas escravista e feudal, consumou a separação entre educação e trabalho.

Contudo, como a história não é algo estável e está sempre em um processo dialético, a relação entre trabalho e educação, com o surgimento do modo de produção capitalista, irá sofrer uma nova determinação. A sociedade capitalista, ao constituir a economia de mercado, isto é, a produção para a troca, inverteu os termos próprios da sociedade feudal que produzia para atender às necessidades de consumo (havendo a troca somente quando havia certo excedente). Mas com o avanço das forças produtivas, intensificou-se o desenvolvimento da economia medieval, provocando o aumento de excedentes e ativando o comércio.

Ainda, segundo Saviani (2007), a estrutura da sociedade deixa de fundar-se em laços naturais para pautar-se em laços puramente sociais, isto é, produzidos pelos próprios homens, é a sociedade contratual, cuja base é o direito positivo, estipulado pelos homens. Com isso, o domínio de uma cultura intelectual impõe-se como exigência generalizada. E a escola, sendo instrumento por excelência para viabilizar o acesso a esse tipo de cultura, é erigida na forma principal, dominante e generalizada de educação. Esse processo assume contornos mais nítidos com a consolidação da nova ordem social propiciada pela indústria moderna no contexto da Revolução Industrial, levada a efeito no final do século XVIII e primeira metade do século XIX.

Conforme Marx (2006), a produção capitalista começa realmente somente quando o mesmo capital individual emprega um número relativamente grande de trabalhadores; de forma que o processo de trabalho seja extenso, gerando uma quantidade relativamente grande de produtos. Um maior número de trabalhadores juntos ao mesmo tempo, no mesmo lugar para produzir algum tipo de mercadoria sobre as ordens de um capitalista, constitui-se, tanto histórica quanto logicamente, no início do modo de produção capitalista.

Destarte, o trabalhador não trabalha mais para si mesmo. Ele agora trabalha para outro indivíduo, neste caso, o capitalista, o burguês, aquele que detém os meios de produção. Nesse sentido, podemos notar que passa a haver maior eficiência das tarefas repetitivas, proporcionada pela quantidade de trabalhadores, pois vários trabalhadores trabalhando ao mesmo tempo provocam uma diminuição do valor do trabalho, ocorrendo o aumento da mais valia absoluta. 
De acordo com Marx apud Angeli (2008), a mais valia absoluta é aquela produzida pelo simples prolongamento da jornada de trabalho, enquanto que a mais valia relativa é aquela que provém da redução do tempo de trabalho necessário para o trabalhador se manter. Ocorre dessa forma uma submissão do trabalho ao capital.

Ainda, conforme Marx (2006), a finalidade do modo de produção capitalista é extrair a maior quantidade possível de mais valia, e consequentemente, de explorar o trabalhador o máximo possível. Mas, no momento em que se extrai a mais valia do trabalhador e este é excluído de qualquer participação na discussão sobre a destinação, organização e planejamento do trabalho, cresce também sua resistência a esta forma de dominação.

Esta exclusão do trabalhador ocorre porque o trabalho deixou de ser a categoria central da produção. Não é ele que domina o processo produtivo, mas sim a máquina. A manufatura tem a sua origem no trabalho artesanal, homogênea ou serial, agrupando em um mesmo lugar os produtores com atividades específicas que concorrem para a fabricação de uma mercadoria. Ela é um espaço organizado de tal modo que os produtores cooperam entre si. No período entre a metade do séc. XVI e no último terço do século XVIII, ela irá proporcionar um forte desenvolvimento econômico e social, conforme Marx (2006) a manufatura desenvolve, portanto, uma hierarquia nas forças de trabalho, à qual corresponde uma escala de salários (MARX, 2006, p. 404).

A manufatura foi a primeira e a principal forma de produção capitalista, agregando trabalhadores de diversas especialidades, para produzirem mercadorias que exigia a cooperação destas várias especialidades, e, por um capitalista que emprega operários para fazer um produto que poderá vir a ser comercializado (ANGELI, 2008).

Desse modo, iniciou-se incessantemente um movimento de quebra do monopólio que o trabalhador tinha do conhecimento sobre o processo de trabalho e a conseqüente capacidade de executá-lo (TAUILE, 2001, p. 63).

Ao se referir ao artesanato Marx demonstra como foi a sua distanciação em relação à manufatura: $\mathrm{O}$ trabalhador e seus meios de produção permaneciam indissoluvelmente unidos, como o caracol e sua concha, e, assim, faltava a base principal da manufatura: a separação do trabalhador de seus meios de produção e a conversão desses meios em capital (MARX, 2006, p. 414).

O processo produtivo da manufatura foi se transformando e o trabalho individual se especializando, de forma que a competência artesanal original foi desaparecendo na medida em que cada trabalhador deixava de fazer todo o trabalho envolvido na produção de cada mercadoria, passando a ser responsável só por algumas ou mesmo uma única operação da linha de produção. 
Logo, o trabalho deixava de ser o elemento de comando do processo de produção, por que a atividade do trabalhador foi reduzida a uma mera abstração de atividade, pois ela é regulada e determinada em todos os aspectos pelo movimento da máquina, e não ao contrário.

O novo processo produtivo constitui-se por uma hierarquia de trabalhadores que correspondem a tarefas e salários diferentes e também diferentes possibilidades de uso da capacidade criativa, sendo ela, no entanto, limitada ou nula para todos os trabalhadores, independente do lugar que este ocupa. O trabalho permanece como elemento fundante da vida social. Mas é determinado e determinante pelo capital, agora assalariado. É o trabalho assalariado que dá a especificidade do capitalismo. O que significa que ele perdeu a centralidade na produção, mas não deixa de ser o elemento fundante na vida social (ANGELI, 2008).

Desse modo, na manufatura a máquina não era um fator central na produção, pois ela aparece esporadicamente, porém, ela ocupa um papel central na produção capitalista. Como afirma Gorz:

\begin{abstract}
Seu objetivo é sempre duplo: substituir uma parte dos operários por máquinas mais complexas e mais eficazes e, portanto, reduzir a quantidade de trabalho para uma mesma produção; mas também, e ao mesmo tempo, substituir a intervenção inteligente do trabalhador por regulamentos e controles automáticos, os quais, mais do que nunca, fazem dos 'operadores' aquelas pessoas agitadas que vêem a máquina impor-lhes inexoravelmente um número preciso de gestos que exigem a maior atenção e a mais completa vacuidade de espírito (GORZ, 2003, p. 153).
\end{abstract}

Neste momento é a máquina que comanda. $\mathrm{O}$ advento da indústria moderna conduziu a uma crescente simplificação dos ofícios, reduzindo a necessidade de qualificação específica, viabilizada pela introdução da maquinaria que passou a executar a maior parte das funções manuais, de acordo com Marx (2006), não partindo do trabalhador o movimento global da fábrica, mas da máquina, pode-se mudar o pessoal a qualquer hora sem interromper o processo de trabalho, ou seja, o processo de trabalho deixa de se fundamentar no elemento subjetivo, o trabalhador, passando a se organizar em torno de um elemento objetivo, a máquina.

Aos poucos, destruiu-se a capacidade produtiva dos trabalhadores no interior do processo de produção, cujas qualificações e virtuosidades não vêm mais da subjetividade dos indivíduos e do trabalho, no entanto, materializa-se agora na máquina (NAPOLEONI, 1981, p. 88).

Manacorda (1991) acentua que a alienação do trabalho produz deformidade, imbecilidade e cretinismo no operário. Ademais, segundo o autor, a condição humana do 
proletariado é um estado imediato de subordinação do operário à máquina, como condição geral da humanidade que dela deriva. Para ele:

A divisão do trabalho condiciona a divisão da sociedade em classes e, com ela, a divisão do homem; e como esta se torna verdadeiramente tal apenas quando se apresenta como divisão entre trabalho manual e trabalho mental, assim as duas dimensões do homem dividido, cada uma das quais unilaterais, são essencialmente as do trabalhador manual, operário e do intelectual (MANACORDA, p. 67, 1991).

As questões intelectuais antes indissociáveis do trabalho manual como ocorriam no artesanato, dele destacam-se, indo incorporar-se às máquinas. A introdução da maquinaria despojou o trabalhador individual de todo talento e habilidade que antes possuía, eliminou a exigência de qualificação específica, mas impôs um patamar mínimo de qualificação geral, equacionado no currículo da escola elementar.

\section{A DICOTOMIA EDUCACIONAL: A EDUCAÇÃO PARA DIRIGENTES E OUTRA PARA DIRIGIDOS}

Até a Primeira Guerra Mundial a organização da produção esteve apoiada em indústrias de base, como as indústrias siderúrgicas, químicas, de máquinas e de equipamentos. A demanda por bens de consumo crescia muito lentamente. Quando o industrial norte-americano Henry Ford pôs em prática em sua fábrica de automóveis as teorias do engenheiro Taylor ${ }^{1}$, teve início nos Estados Unidos uma mudança significativa nos modos de produção.

A teoria propunha uma intensificação da divisão do trabalho, fracionando as etapas do processo produtivo de forma que o trabalhador desenvolvesse tarefas especializadas e repetitivas, consistindo basicamente em controlar os tempos e os movimentos dos trabalhadores com o objetivo de aumentar a produtividade no interior das fábricas.

Defendia, ainda, o aprofundamento da divisão entre a concepção e a execução de qualquer artigo industrial, ou seja, entre trabalho intelectual, reservado aos dirigentes e funcionários com alto nível de especialização, e trabalho manual, reservado aos operários das linhas de montagem dos automóveis, cujas peças chegavam até os operários que, parados, executavam sempre as mesmas tarefas referentes a cada parte do carro.

A sociedade estava diante de uma nova forma de organização do trabalho.

Gramsci, em seu texto Americanismo e Fordismo (1980) observa que: 
É relativamente fácil racionalizar a produção e o trabalho, combinando habilmente a força (destruição do sindicalismo operário de base territorial) com a persuasão (altos salários), benefícios sociais diversos, propaganda ideológica e políticas habilíssimas [...] A hegemonia nasce da fábrica e não tem necessidade para exercer-se senão de uma quantidade mínima de profissionais intermediários da política e da ideologia (GRAMSCI, 1980, p. 396).

Gramsci toma os conceitos de indústria e industrialismo, de racionalização, de técnica e tecnologia, apresentando uma correspondência entre a estrutura material ou objetiva e entre processos culturais e subjetivos, entre a força manual e a atividade intelectual, entre processo de "industrialização" e da "formação do homem" e finalmente entre sociedade e aprendizagem, numa rede complexa de exploração do trabalhador (ANGELI, 2008).

Foi intervindo na realidade e disciplinando-a que o fordismo e o americanismo transformaram o modo de ser do homem:

$\mathrm{Na}$ América, a racionalização do trabalho e o proibicionismo estão conectados indubitavelmente: as pesquisas dos industriais sobre a vida íntima dos operários, os serviços de inspeção criados por algumas empresas para controlar a "moralidade" dos operários, são necessidades de um novo método de trabalho, um novo tipo de trabalhador e de homem (GRAMSCI, 1980, p. 382).

Materializa-se um novo modo de vida. Gesta-se uma nova classe trabalhadora e uma nova cultura para a adaptação do trabalhador ao trabalho fabril, assim:

\begin{abstract}
A expressão "consciência do fim" pode parecer pelo menos espirituosa para quem recorda a frase de Taylor sobre o "gorila domesticado". Efetivamente, Taylor exprime com cinismo brutal o objetivo da sociedade americana; desenvolver ao máximo, no trabalhador, as atitudes maquinais e automáticas, romper o velho nexo psicofísico do trabalho profissional qualificado, que exigia uma determinada participação ativa da inteligência, da fantasia, da iniciativa do trabalhador, e reduzir as operações produtivas apenas ao aspecto físico maquinal (GRAMSCI, 1980, p. 396-397).
\end{abstract}

No entanto, de acordo com Gramsci (1980), essa ruptura com o nexo psicofísico do trabalho profissional qualificado, na realidade, não se trata de novidades originais, trata-se somente da fase mais recente de um longo processo que começou com o próprio nascimento do industrialismo.

Ademais, para Gramsci (1980), é, sobretudo, o aparato estatal que sustentação as essas formas, isto é, é o Estado Liberal que garante a legalidade e a institucionalidade da "hegemonia americana”. Está colocado o novo método de produção cuja raiz está na implantação da máquina como elemento capaz de produzir em massa, respondendo satisfatoriamente às demandas da produção. 
Preenchido o requisito da escola elementar, os trabalhadores estavam em condições de conviver com as máquinas, operando-as sem maiores dificuldades.

Contudo, além do trabalho com as máquinas, era necessário também realizar atividades de manutenção, reparos, ajustes, desenvolvimento e adaptação a novas circunstâncias. Isto é, havia também certas tarefas específicas que exigiam certo preparo intelectual específico. Esse espaço foi ocupado pelos cursos profissionais organizados no âmbito das empresas ou do sistema de ensino, tendo como referência o padrão escolar, mas determinados diretamente pelas necessidades do processo produtivo.

Sobre a base comum da escola primária houve uma bifurcação entre as escolas de formação geral e as escolas profissionais. A referida separação teve uma dupla manifestação: a proposta dualista de escolas profissionais para os trabalhadores e "escola de ciências e humanidades" para os futuros dirigentes; e a proposta de escola única diferenciada, que efetuava internamente a distribuição dos educandos segundo as funções sociais para as quais se os destinavam em consonância com as características que geralmente decorriam de sua origem social (SAVIANI, 2007, p. 159).

$\mathrm{Na}$ verdade, o que ocorreu foi a divisão dos homens em dois grandes campos devido a este sistema escolar: aqueles das profissões manuais para as quais se requeria uma formação prática, limitada á execução de tarefas delimitadas, dispensando o domínio teórico, e aqueles das profissões intelectuais para as quais se requeria o amplo domínio teórico a fim de preparar as elites e representantes da classe dirigente para atuar nos diferentes setores da sociedade.

A burguesia construiu propostas de educação para o trabalho nos vários âmbitos da sociedade capitalista, ao longo da história, como podemos notar neste fragmento de Tracy, escrito em 1802:

Em toda sociedade civilizada existem necessariamente duas classes de pessoas: a que tira sua subsistência da força de seus braços e a que vive da renda de suas propriedades ou do produto de funções onde o trabalho do espírito prepondera sobre o trabalho manual. A primeira é a classe operária; a segunda é aquela que eu chamaria a classe erudita. Os homens da classe operária têm desde cedo necessidade do trabalho de seus filhos. Estas crianças precisam adquirir desde cedo o conhecimento e, sobretudo o hábito do trabalho penoso a que se destinam. Não podem, portanto, perder tempo nas escolas [...] Os filhos da classe erudita, ao contrário, podem dedicar-se a estudar durante muito tempo; tem muita coisa a aprender para alcançar o que se espera deles no futuro. Necessitam de certo tipo de conhecimentos que só se pode apreender quando o espírito amadurece [...] Esses são fatos que não dependem de qualquer vontade humana; decorrem necessariamente da própria natureza dos homens e da sociedade: ninguém está em condições de poder mudá-los [...] Concluamos, então, que em todo o Estado bem administrado e no qual se dá a devida atenção à educação dos cidadãos, deve haver dois sistemas completos de instrução que não tem nada em comum entre si (DESTUTT, M. C. de Tracy APUD FRIGOTTO, 2004, p. 15). 
Essa concepção de educação e trabalho é exposta atualmente de forma mais sutil, no entanto, ocorre a mesma divisão, a mesma dualidade. Ainda, conforme Frigotto (2004), o trabalho é compreendido não como uma única fonte de produção de valor e que permite, portanto, nas relações de produção capitalista, a expropriação, a mais-valia, mas como uma atividade que cria riqueza indistintamente para todos os homens.

\section{CONSIDERAÇÕES FINAIS}

Pelo exposto, pode-se observar que as ideologias que predominam entre as classes superiores, entre as elites, disseminam na sociedade e criam um consenso que é pelo trabalho que os patrões chegam a acumular a riqueza e, portanto, é pelo trabalho árduo, disciplinado, que os trabalhadores podem ascender socialmente e, dependendo de seu esforço, tornarem-se patrões. No bojo das teorias neocapitalistas, que incluem as perspectivas de cogestão e participação nos lucros, vai se reforçando a ideia de que a superação das desigualdades entre as classes é possível, sem a supressão da mais-valia, sem uma quebra ou ruptura da lógica do valor.

Esta interiorização da ideia de trabalho vem comandando as políticas educacionais. $\mathrm{O}$ trabalho aparece como uma virtude universal, pela qual a acumulação de capital é legítima (MARTINS, 2000). Por esse motivo, é de salutar importância entender a questão do trabalho e da educação enquanto questões históricas, sua dualidade somente é compreendida se a sua dimensão histórica e sua forma assumida no capitalismo forem levadas em consideração.

A divisão do trabalho é, historicamente, exigida pelo processo do trabalho manufatureiro ou industrial. O desenvolvimento da máquina incorpora a esta habilidade do ofício e os conhecimentos que antes eram possessão do trabalhador.

A ciência e os conhecimentos passam a ser propriedade do capital, e o trabalhador se encontra enfrentando-os. Tal como indica Engels (2004), vigiar as máquinas, renovar os fios quebrados, não são atividades que exijam do operário algum esforço do pensamento, contudo, por outro lado, impedem-no de ocupar o seu espírito com outra coisa. Ou seja, a apropriação dos meios produtivos, da ciência e da cultura permite a exploração, sendo que a limitação de seu conhecimento mutila e reprime o desenvolvimento de suas faculdades criadoras. Assim:

A ignorância é a mãe da indústria, bem como da superstição. A reflexão e a imaginação estão sujeitas ao erro; mas o hábito de mexer o pé ou a mão não depende nem de uma nem de outra. É por isso que as manufaturas prosperam mais onde se raciocina menos e onde passam bem sem a inteligência, apesar de a oficina poder ser considerada como uma máquina, cujas partes são os homens (MARX \& ENGELS, 2004, p. 25). 
Porém, o que devemos refletir é que Marx e Engels escreveram num momento em que o desenvolvimento das forças produtivas era reduzido. Sabe-se que os primeiros tempos da industrialização se caracterizaram pelo aumento do trabalho simples - com a perda da capacidade artesanal existente - a extensão do trabalho infantil e feminino em condições de vida inferiores às existentes nas formações sociais agrárias. No entanto, não ignoravam que, primeiro, esta situação teria de ser transitória e, segundo, que o desenvolvimento cultural era necessário para a consolidação e posterior desenvolvimento das forças produtivas.

Destarte, longe de introduzir um maior nível de "semicultura", o capitalismo exigiu uma crescente capacidade intelectual de todos os indivíduos, estendendo ao sistema escolar, institucionalizando e aprofundando-o. Mas, o que vigora no capitalismo é e o predomínio de formas para que o sistema perpetue e o individuo permaneça cada vez mais passivo, e a educação é uma destas formas.

Entretanto, Marx e Engels não pretendem retornar a situações "pré- capitalistas", não desejam terminar com a escola para voltar a uma instrução natural, não pretendem voltar atrás, mas ir à frente, superar o capitalismo, e essa superação só pode se realizar a partir do próprio capitalismo, acentuando suas contradições, desenvolvendo suas possibilidades, isto é, suas propostas se movem num horizonte bem concreto: criticar a instituição escolar e mudá-la. 


\section{REFERÊNCIAS}

ANGELI, José Mário. Princípio da Formação Humana: A Filosofia da Práxis. In: Currículo e Formação Humana. Editora CRV, Curitiba, 2009.

. A Relação Entre a Educação dos Trabalhadores e o Processo Produtivo: Eixo Norteador da Formação Profissional. In: O Ensino Médio Integrado à Educação Profissional: Concepções e Construções a Partir da Implantação na Rede Pública Estadual do Paraná. Curitiba: SEED - PR, 2008.

FRIGOTTO, Gaudêncio. Trabalho, conhecimento, consciência e a educação do trabalhador: impasses teóricos e práticos. In: Carlos $\mathrm{M}$. Gomez (et al). $5^{\mathrm{a}}$ ed. Trabalho e Conhecimento: dilemas na educação do trabalhador. SP: Cortez/Autores Associados, 1989.

GORZ, A. Metamorfose do Trabalho: Busca do sentido, crítica da razão econômica. SP: Ed. Annablume, 2003.

. Maquiavel, a política e o Estado Moderno. RJ: Civilização Brasileira, 1980.

LUKÁCS, G. Ontologia do Ser Social: Os Princípios Ontológicos Fundamentais de Marx. Trad. Carlos Nelson Coutinho. SP: Ciências Humanas, 1979.

MANACORDA, M. A. Marx e a Pedagogia Moderna. São Paulo: Cortez/Autores Associados, 1991.

MARX, Karl; ENGELS, F. Ideologia Alemã. Tradução de José Carlos Bruni e Marco Aurélio Nogueira. São Paulo, Editora HUCITEC,1996.

Centauro, 2004.

. Textos sobre Educação e Ensino. Tradução de Rubens Eduardo Frias. $4^{\text {a }}$ ed. SP: . O Manifesto do Partido Comunista. 2006.

. O Capital, in MEW, vol. 25.

- O Capital: crítica da economia política. Livro I. Tradução de Reginaldo Sant'Anna.

24. Ed. RJ: Civilização Brasileira, 2006, v. 1.

. O Capital. São Paulo, Difel, 6 vols. , 1982.

MARTINS, Marcos Francisco. Ensino Técnico e Globalização: cidadania ou submissão? Campinas, SP: Autores Associados, 2000.

MESZAROS, I. A Teoria da Alienação em Marx. SP: Boitempo, 2006.

NAPOLEONI, C. Lições sobre o Capítulo VI (inédito) de Marx. Tradução de Carlos Nelson Coutinho. São Paulo: Ciências Humanas, 1981.

SAVIANI, Dermeval. Trabalho e Educação: Fundamentos Ontológicos e Históricos. Revista Brasileira de Educação. V. 12, n. 34 jan./abr. 2007.

TAUILE, J. R. Para (re) construir o Brasil contemporâneo: trabalho, tecnologia e acumulação. Rio de Janeiro: contraponto, 2001. 